\title{
Marcel Berger Remembered
}

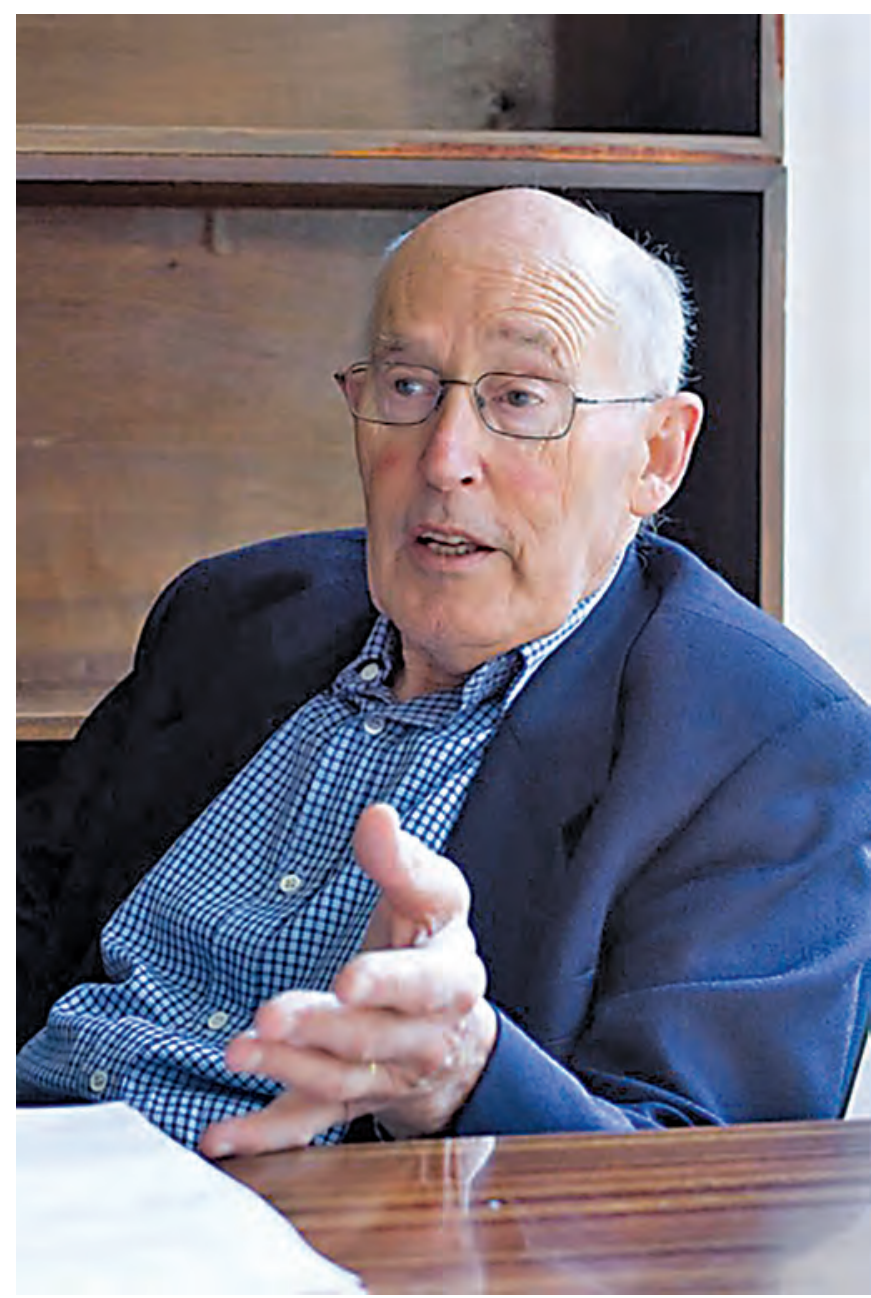

Claude LeBrun, Editor and Translator

EDITOR'S NOTE. Claude LeBrun has kindly assembled this memorial for Marcel Berger. This month also marks the conference "Riemannian Geometry Past, Present and Future: An Homage to Marcel Berger" at IHÉS.
Claude LeBrun is professor of mathematics at Stony Brook University. His email address is claude@math. stonybrook. edu.

For permission to reprint this article, please contact:

reprint-permission@ams.org.

DOI: http://dx.doi.org/10.1090/noti1605

\section{Gérard Besson}

Marcel Berger, ${ }^{1}$ one of the world's leading differential geometers and a corresponding member of the French Academy of Sciences for half a century, passed away on October 15, 2016, at the age of eighty-nine.

Marcel Berger's contributions to geometry were both broad and deep. The classification of Riemannian holonomy groups provided by his thesis has had a lasting impact on areas ranging from theoretical physics to algebraic geometry. His 1960 proof that a complete oriented even-dimensional manifold with strictly quarter-pinched positive curvature must be a topological sphere is the

Gérard Besson is CNRS Research Director at Institut Fourier, Université Grenoble, France. His email address is g.besson@ujf -grenoble.fr.

${ }^{1}$ Pronounced bare-ZHAY. 


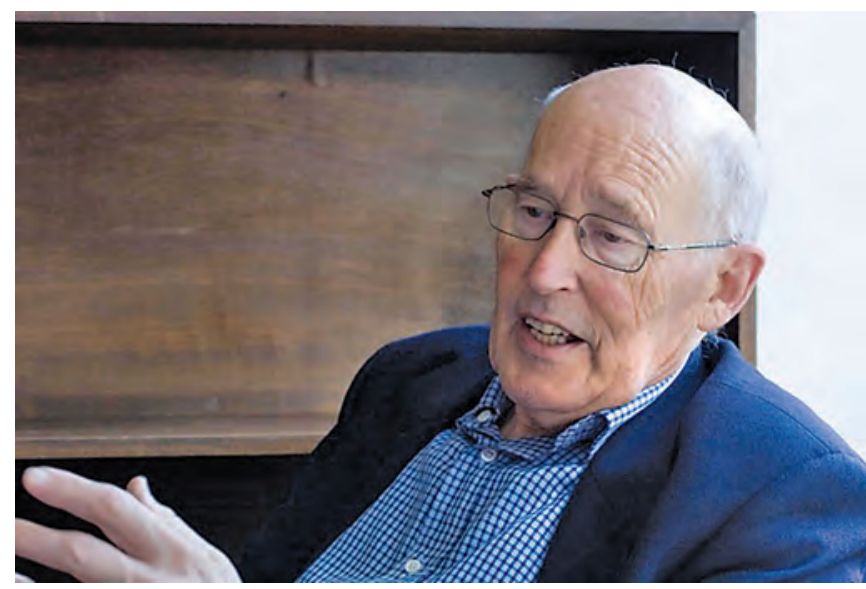

Marcel Berger, during his directorship (1985-1994) of the IHÉS, in Bures-sur-Yvette, France.

direct ancestor of a vast sector of subsequent research in global Riemannian geometry. Through his many students and collaborators, he created a school which carried the torch of differential geometry into a new era. Under his leadership, a group of mathematicians collaborating under the pseudonym of Arthur L. Besse produced several landmark books [1], [19], [20] that inspired a ferment of research activity in connection with key topics of interest: the study of Riemannian manifolds whose geodesics are all closed, links between volume and injectivity radius [11], and the theory of Einstein manifolds [10]. He has also left us an impressive series of popular and pedagogical books, as exemplified by his massive treatise $A$ Panoramic View of Riemannian Geometry [14]. His efforts in this last vein also included a campaign to increase the understanding of the work of Mikhail Gromov.

Born in Paris on April 14, 1927, Berger was a student at the École Normale Supérieure from 1948 until 1953, when he was awarded a research assistantship by the $\mathrm{CNRS}^{2}$ after distinguishing himself in a national competition. In 1954, under the supervision of André Lichnerowicz, he then defended his doctoral thesis, which proved a landmark classification of the holonomy groups of Riemannian manifolds.

After spending the academic year 1956-57 at MIT, Berger was promoted to the rank of research scientist by the CNRS. In 1958 he then accepted a junior appointment at the University of Strasbourg, where he was eventually promoted to full professor in 1962, shortly after his return from a year in Berkeley. After moving to a professorship in Nice for two years, he then moved again in 1966, this time to the University of Paris, which at that time was still a single, unified institution. When the university was broken into smaller units in the wake of the 1968 student riots, Berger was attached to the University of Paris VII, at Jussieu, and was promoted to the rank of

${ }^{2}$ The Centre national de la recherche scientifique is the French government's main agency for the support of fundamental scientific research. Unlike the American NSF, the CNRS supports a large network of scientists on a permanent basis. research director by the CNRS. He served as president of the French Mathematical Society (SMF) during the period of 1979-80 and in this capacity helped oversee the foundation of the International Center for Mathematical Workshops (CIRM) in Luminy. In 1985 he then became director of the Institute for Higher Scientific Studies (IHÉS) in Bures-sur-Yvette, a position in which he served until 1993, when he was succeeded by his former student Jean-Pierre Bourguignon.

The mathematical community will remain eternally indebted to Marcel Berger for his marvelous contributions to our mathematical heritage, which have substantially transformed the field of differential geometry.

\section{Misha Gromov}

\section{Inspired by Marcel Berger: Recollections}

(1955-1995) There is no need for me to say anything about Marcel's famous 1/4-pinching theorem, his discovery of collapse with bounded curvature, his contributions and leadership in the field of spectral geometry, or his classification of special holonomy groups-everybody in our universe ${ }^{3}$ is aware of these.

However, it is perhaps worth mentioning that the last was cited as a source of inspiration by Jim Simons when the Légion d'Honneur was bestowed on him by the French ambassador in New York.

(1972) Systolic Inequalities and Calibrations. In a couple of articles from this period, Marcel proposed a new conceptual (systolic) rendition of Loewner's early results on surfaces. With characteristic modesty, he attributed the idea to René Thom.

In his evaluation of systoles of particular manifolds, I believe Marcel made the very first use ever, in the context of quaternionic spaces, of the method of calibrations and proved that

The quaternionic projective subspaces $\mathbb{\mathbb { P } ^ { k }} \subset \mathbb{\mathbb { Q } ^ { n }} \mathbb{P}^{n}$ are volume minimizing among all $4 k$-cycles not homologous to zero in $\mathbb{A P}^{n}$.

(1978) Blaschke Conjecture for Spheres. If a Riemannian manifold $X$ homeomorphic to $S^{n}$ has diameter equal to its injectivity radius, then $X$ is isometric to a standard "round" (constant-curvature) sphere.

Marcel's dazzlingly simple proof of this (which involves a contribution by Jerry Kazdan, who proved a key analytic inequality suggested by Marcel), hardly takes half a page.

Mikhail Gromov is Jay Gould Professor of Mathematics at the Courant Institute, New York University, and professor emeritus at Institut des Hautes Études Scientifiques, France. His email address is gromov@ihes.fr.

${ }^{3}$ Here, "our universe" means the "community of differential geometers." 
(1980) Isoembolic Inequality. Among all $n$-dimensional manifolds with a given injectivity radius, the round sphere has the least volume.

(2000?) Buying Cheese in Paris. One day, while a guest at Marcel's apartment in Paris, I tried a piece of cheese whose flavor far excelled anything I had ever tasted before. When I asked Marcel where this cheese came from, he could not hide his surprise at the impudence of my question.

Of course-he said-it is from Quatrehomme. Do you think we would serve our guests cheese from Dubois?

Please,-I said-what is the name of this cheese, and where is this boutique? I want to go there and buy this cheese myself.

Marcel literally froze, with his mouth open.

Yourself? Are you kidding? Do you imagine that you will just GO to Quatrehomme and BUY Pontl'Évêque??!!

Why not? What could be complicated about buying cheese?

Of course, it is simple. But getting GOOD cheese takes time-about a year, maybe, a half-year if you really know how to go about it.

By this time, it was my own mouth that was agape. Taking pity on my ignorance, Marcel then explained,

A respectable cheese has a narrow time window of 3-4 days during which it is good to eat. Only the proprietor of a boutique knows which of his cheeses are ripe. If you are a serious customer, he will tell you which cheeses you should buy on a particular day.

To gain his respect you have to come to the shop regularly, at least once a week, and buy a couple kilograms of several cheeses. Besides-and this is crucial-you should show some understanding of cheese.

Eventually, he will accept you, and then you will start getting cheeses like the one you have just tasted.

Ourselves, concluded Marcel-

We do it together. Five families! One of us, always the same man, has gone to Quatrehomme for five years. Simple, and it works!

\section{Jim Simons}

I very much admired Marcel Berger. He was an exceptional mathematician and a gracious individual. His death is a sad loss to the community.

Jim Simons is chairman at Renaissance Technologies and research professor of mathematics at Stony Brook University.
My thesis in 1961 was a direct result of his remarkable work on holonomy in irreducible Riemannian manifolds, in which he enumerated all possible holonomy groups. These all turned out to be transitive on the unit sphere, which led to the question of how one could prove this directly without recourse to his list. Such a proof was provided by my thesis.

Berger also proved the first pinching theorems in Riemannian geometry, proving that an even-dimensional compact Riemannian manifold whose sectional curvature is strictly

\section{This was seminal work.} between $\frac{1}{4}$ and 1 is necessarily homeomorphic to the sphere and later showing that, if we don't insist that the inequalities be strict, the only exceptions we've now allowed in are just the symmetric spaces of rank 1 . This was seminal work. I showed it to my first student, Jeff Cheeger, and it inspired him to write an excellent thesis. Jeff then went on to develop these ideas further, initially alone and later in collaboration with Detlef Gromoll. This illustrates the way that Berger's ideas quickly led to an important body of work, relating curvature to the topology of Riemannian manifolds.

\section{Jeff Cheeger}

Marcel Berger was one of the leading Riemannian geometers of the mid-twentiethth century and for many years the dean of French differential geometry. His beautiful contributions to metric geometry, especially those from 1955 to 1980, provided a high standard for the period and played a major role in setting the stage for the subject's next explosive phase of development. A few of the highlights were the even-dimensional sphere theorem with (sharp) 1/4-pinching, associated results such as the minimal diameter rigidity theorem (arguably, the first global rigidity theorem), the sphere theorem with pinching slightly below $1 / 4$ (via a compactness/contradiction argument), and his comparison theorem, known as "Rauch II"; for details, see [4], [6], [12], [7].

With hindsight, Berger's lemma, concerning pairs of points at maximum distance, to some extent foreshadowed the Grove-Shiohama-Petersen theory of critical points of distance functions, which has had a number of very remarkable applications.

Berger's example of a collapsing sequence of positively curved metrics on $S^{3}$ is now viewed as the first nontrivial example of collapse with bounded curvature. It is very illuminating and remains required reading for anyone interested in learning the theory of collapse with bounded curvature. To fully appreciate its significance, one must be aware that at the time, Riemannian geometry was very short of "meaningful" examples. The point for Berger was that it demonstrated that the known lower bound estimates on the injectivity radius in the odd-dimensional simply connected case no longer held for pinching $<1 / 9$.

Jeff Cheeger is Silver Professor of Mathematics at Courant Institute, New York University. His email address is jc9@nyu. edu. 


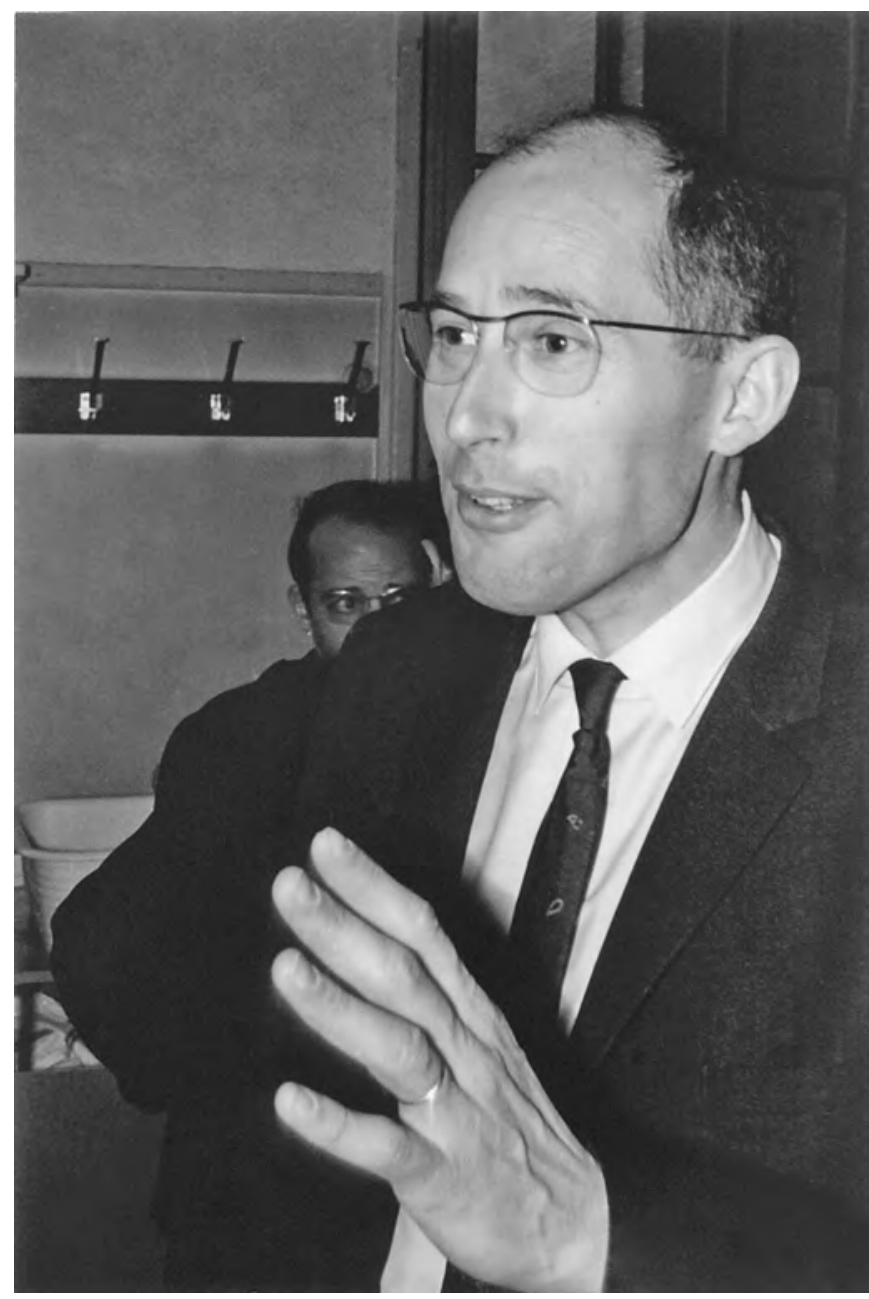

Berger in Paris in 1968.

Berger's sharp upper bound for the injectivity radius in terms of the volume [9], [11] is remarkable in that curvature does not enter. Closely related work with Jerry Kazdan was used in their proof [18] of the Blaschke conjecture: Manifolds for which the cut locus of every point consists of a single point are isometric to standard spheres.

As a graduate student interested in learning Riemannian geometry, I was enormously impacted by Berger's work. It was inspiring. I became excited by the idea that one could make progress in geometry just by drawing simple pictures, staring at them, waiting for the light to go on, and at the appropriate point bringing in some ordinary differential equations and perhaps some topology. A bit later, when I was a postdoc at Berkeley, I was taken aback when Dennis Sullivan said, "Don't you think that it's just a little bit naive?"

From my personal perspective, Riemannian geometry was virtually a perfect subject. It had received tremendous impetus from the geometrical tools introduced by Rauch, Berger, Klingenberg, and Toponogov, and a bit later by Gromoll and Meyer. Yet it was still in a very underdeveloped state. One could get started without having to know all that much. Analysis was not playing the central role that it came to play after the revolutionary impact of the work of Yau. That was just as well, since at the time, I didn't know much analysis. During the first few years after my degree, almost all of my work was in metric geometry, much of it in collaboration with Detlef Gromoll. My book with David Ebin, Comparision Theorems in Riemannian Geometry, contained an exposition of many of the key results up to 1975, including, of course, various theorems of Berger.

Berger's fundamental classification of the candidates for holonomy groups of Riemannian manifolds, a tour de force, was accomplished [2], [3] during the period 195355. An unexplained consequence was the observation that if the holonomy group of $M^{n}$ acts irreducibly, then either it acts transitively on the unit sphere or $M^{n}$ is a symmetric space of rank $\geq 2$. In his thesis, Jim Simons gave an algebraic proof of this fact, one which avoided the classification. Later, Jim became my teacher and directed me to the study of comparison theorems. He said, "There isn't too much else going on in geometry right now." (And this just slightly before his own spectacular work on minimal varieties and Chern-Simons invariants!)

Berger visited Berkeley for the "big" Global Analysis Summer Institute, which lasted for three weeks during the summer of 1968. I was just finishing up my postdoc, and at some point I was told that the great man would like to meet with me to discuss geometry. Excited but a bit nervous, I asked if I could bring along my mathematical big brother, Detlef. Naturally, it turned out that Marcel (as I will now call him) was kind and friendly.

A few summers later, at Marcel's invitation, Detlef and I spent several weeks in Paris. He was surrounded by a large and impressive group of students, including Jean-Pierre Bourguignon, with whom we later became good friends. During the visit we asked Marcel if he could recommend a restaurant. He sent us to a place with the amusing name Le Sanglier Bleu, where we had a great meal and a super good time.

It turned out that Marcel had become interested in the spectrum of the Laplacian, especially the question of what geometric information might be contained in the asymptotic expansion of the trace of the heat kernel The coefficients in this expansion are local invariants involving the curvature and successively more of its covariant derivatives. Attention had been drawn to them by the visionary paper of McKean and Singer, ${ }^{4}$ in which they proposed the heat equation method for proving the Atiyah-Singer index theorem for the operator $d+\delta$ : $\Lambda^{\text {even }} \rightarrow \Lambda^{\text {odd }}$, whose index is the Euler characteristic, and expressed the hope that a "fantastic cancellation" in the coefficients would lead to the Chern-Gauss-Bonnet integrand.

Something significant which came out of the Laplacian project was Marcel's book with Gauduchon and Mazet, Le spectre d'une variété riemannienne [17]. During our visit, he told me, "My less strong students, I put them on the

${ }^{4}$ Curvature and the eigenvalues of the Laplacian, J. Diff. Geometry 1 (1967), 43-69. 
spectre." This was puzzling, since it seemed to me that he didn't have any "less strong" students. Also, I was vaguely aware of the Ray-Singer conjecture on the equality of Reidemeister torsion and analytic torsion, which struck me as very exciting, though I could only understand it in a superficial way. I knew that I needed to learn more about the heat kernel, and Le spectre d'une variété Riemannienne was the ideal place to start. I decided to make an intensive study of this book, which worked out very well.

In the period 1980-2000, I

\section{an aversion to taking the credit for his own mathematical} encountered Marcel many times during stays at IHÉS, where for most of that time he was the director. As usual, he was nice and friendly, but at some point it struck me that his personality had a side which seemed slightly "quirky," though not quite in a way on which I could put my finger. One thing I did eventually realize was that he had an aversion to taking the credit for his own mathematical contributions.

Marcel wrote a large number of excellent expository works on different aspects of geometry. A number of them were at an "elementary" level, though perhaps from a somewhat advanced standpoint. Most notable for me were the monumental A Panoramic View of Riemannian Geometry [14] and the shorter Riemannian Geometry during the Second Half of the Twentieth Century [13]. While he was preparing these, we had quite a few email exchanges. I was impressed by his strong desire to get the history right, no matter how much back and forth it took, and once again by his aversion to explicitly awarding himself the credit for his own work. On several occasions I was forced to insist, "But, Marcel, it was you who did that!"

Marcel was an outstanding mathematician and a unique character. I miss him.

\section{Jean-Pierre Bourguignon}

I am indebted to Marcel Berger for a multitude of things that have decisively influenced my mathematical life. These reflect not only his unique place in the rich landscape of late-twentieth-century French mathematics but also his unique personal qualities: his generosity, his geometric vision, his international network of friendships, his modesty, his high standards, and his strong commitment to public service.

Having given up previous academic positions in Strasbourg and Nice, Marcel Berger became a professor in Paris just in time to experience the tumult of the 1968 student riots. Perceiving that society was undergoing a transformational shift in relations between generations, he concluded that it was imperative that he overcome

Since 2014, Jean-Pierre Bourguignon is president of the European Research Council, Brussels, Belgium. His email address is jpb@ihes.fr. his natural shyness in order to establish a seminar and develop strong working bonds with a group of research students. One consequence was that he agreed in 1969 to become my thesis adviser, taking over a role previously fulfilled by Gustave Choquet. This turn of events was in part made possible by the fact that I had attended his graduate course on the spectrum of a Riemannian manifold, notes on which were at that time becoming famous under the acronym BGM (for Berger-Gauduchon-Mazet). But I came to Riemannian geometry largely by default after failing to convince any leading Parisian expert on classical mechanics to supervise my project of solving the Euler equations by applying Arnold's strategy to the group of diffeomorphisms - a strategy that David Ebin and Jerrold Marsden in any case successfully developed soon afterwards. This left me to master Riemannian geometry from scratch, having to learn almost everything.

The next year, however, because I was Berger's only protégé to currently hold a CNRS attaché de recherche position, Marcel bestowed upon me the amazing gift of a significant block of his time each week. Every Tuesday he would spend the whole day trying to tell me everything he knew about geometry-and that, of course, was vast: curvature and topology, the geometry of geodesics, holonomy, Kähler geometry, the Calabi conjecture, etc. The topics ran the gamut of geometric research, and the approach he took was holistic.

Marcel waxed enthusiastic when I suggested that David Ebin might spend a year in Paris teaching us global analysis. He had previously collaborated with David during a visit to Berkeley, and Marcel now clearly foresaw the remarkably transformative role that nonlinear partial differential equations would surely play in the development of geometry in the years to come.

Marcel insisted that his Wednesday seminar (which, per local tradition, also bore his name) should be a real working seminar, with a year-long theme providing the focus for the lectures. While he would always have the last word when it came to the choice of topics, he consistently gave us all the opportunity to present our most recent results. We learned a huge amount, because Marcel's ambition was for everyone to become acquainted with every topic necessary for a deeper understanding of geometry. He nonetheless gave his students plenty of leeway to develop their own research programs. For example, he in no way objected to my own decision to dedicate my thèse d'État to the development of a "stratification of the space of Riemannian structures."

Berger developed a network of friendships with international mathematical leaders and was always eager to see his students benefit from this network. His strong ties with Wilhelm Klingenberg gave us the benefit of participating in the "Small Arbeitstagung in Differential Geometry," which provided us with our first real international exposure, since, paradoxically enough, Bonn was more international than Paris at the time. Then, in June 1972, a visit to Paris by Jim Simons, who had re-proved Berger's classification of Riemannian holonomy from a new viewpoint, afforded me the opportunity to spend 
the academic year 1972-1973 in Stony Brook, which had become the Mecca of differential geometry, with no fewer than fourteen specialists on its faculty. Spending a year in the US had a decisive impact on my own career; it not only resulted in my first joint work with $\mathrm{S}$. T. Yau, who was there in his first professorial position, but also allowed me to attain a more global perspective on my own work. This visit was followed by a summer spent at Stanford at the invitation of Robert Osserman, again on Berger's recommendation. These contacts then led to several other opportunities. For example, participation in the Differential Geometrie im Grossen meetings at Oberwolfach, organized by S.-S. Chern and Klingenberg, became the source of many unforgettable experiences and gave me privileged access to Chern because of the latter's considerable respect for Berger. The good relations Marcel developed with Isadore Singer during a stay at MIT opened other doors for me and led to inspiring discussions of the relationship between geometry and physics. Similarly, Berger's close ties with Shingo Murakami led to my first visit to Osaka in 1979, followed by many other trips to Japan; Berger's work is highly influential in Japan and has provided the starting point for many papers by leading Japanese mathematicians. And the list of course goes on, as Berger's international contacts put me in contact with such figures as Eugenio Calabi, Manfredo do Carmo, James Eells, Jerry Kazdan, and Shoshichi Kobayashi, to name only a few.

Besse was
intended as a
direct
challenge to
Bourbaki.

The "Berger school" eventually chose to cloak itself under the collective pseudonym of Arthur L. Besse after a foundational "Round Table" workshop in the village of Besse-enChandesse. Besse's last name was of course provided by the village, while his first and middle names of Arthur and Lancelot came from the medieval legends of the Knights of the Round Table. ${ }^{5}$ In a very real sense, Besse was intended as a direct challenge to Bourbaki: Besse's philosophy emphasizes the need to mobilize many different specialized bodies of knowledge to attack deep questions, in complete contrast to the model provided by Bourbaki's Éléments de mathématiques. Indeed, the approach adopted by Besse was rather similar to the one previously advocated by André Weil in his Publications de l'Université de Nancago, ${ }^{6}$ much to the discomfiture of some of Weil's Bourbaki collaborators. In any case, Besse's approach soon justified itself by bearing tangible fruit. It also became evident that this exciting and

\footnotetext{
${ }^{5}$ While nearly every child in the English-speaking world seems to have heard tales of King Arthur, Lancelot, and the Knights of the Round Table, these characters are perhaps best known in France to those with something of a scholarly interest in the medieval French romances that are the main sources of Arthurian legend.

${ }^{6}$ Nancago refers to the two cities where Weil taught at the time: Nancy and Chicago.
}

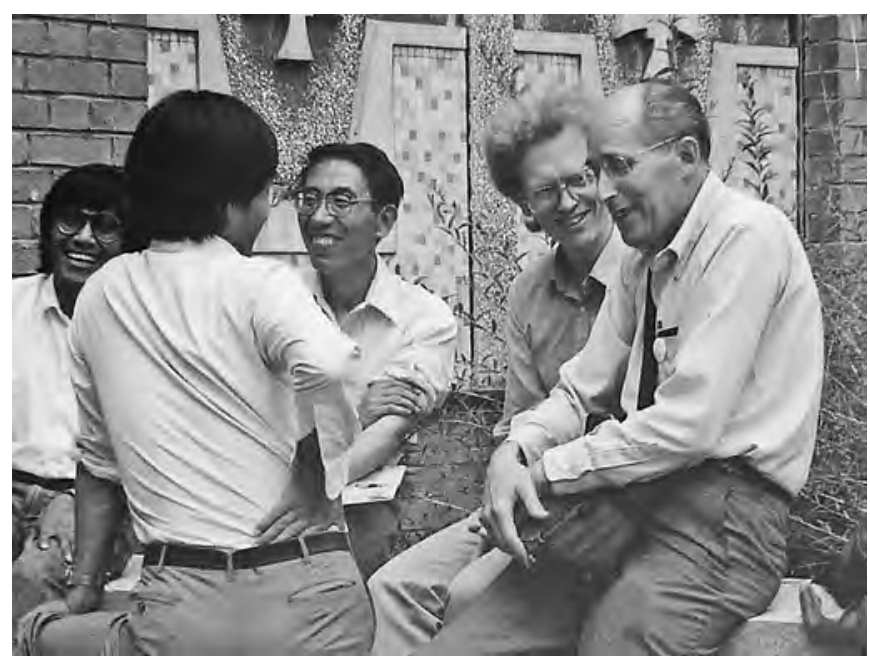

Berger (right) talks with Hermann Karcher at Oberwolfach in 1982. Also present: Maung Min-Oo (left) and Shoshichi Kobayashi (middle).

successful venture would not have been possible without Berger's leadership and his generous, open personality.

Of course, much more could be said. Marcel's conviction that Mikhail Gromov's ideas would completely transform differential geometry was quickly borne out by events, and the powerful impact of this new perspective on French mathematics became particularly evident after Gromov decided to settle at the IHÉS. Berger went on to become a tireless and persuasive public advocate of Gromov's ideas and vision. ${ }^{7}$

But here I would really have to enter into yet another chapter of Berger's life, namely, his directorship of the Institut des Hautes Études Scientifiques (IHÉS). Although I eventually became Berger's successor there, I am actually less qualified to discuss this period than certain other contributors to this collection of reminiscences, and I will therefore leave it to them to comment on this important part of Marcel's life and career. Paradoxically, much of my prior knowledge regarding the running of the institute was gleaned from conversations with Marcel's predecessor, Nicolaas Kuiper, during the period of his own mandate. Since the duties of the director of the IHÉS do not include the selection of his successor, I next discussed my views concerning the institute's future, not with Marcel, but rather with the institute's permanent professors. Only when my term as director was about to start and upon my return from an extended stay at MSRI did Marcel share with me some of his vision and experience concerning the institute.

Marcel's absence presents us all with a profound loss. We will miss his frequent exhortations to think geometrically, as well as his gentle manner and modest attitude, which will remain a model for us all.

\footnotetext{
${ }^{7}$ Berger's masterful survey of Gromov's work, "La géométrie selon Gromov," a lecture delivered at the IHÉS in 2000 in celebration of Gromov's Balzan Prize, was recorded by François Tisseyre and is available as a free video at https://vimeo. com/188585117.
} 


\section{Dennis Sullivan}

Marcel Berger and his wife, Odile, provided a warm family atmosphere for the scientists at IHÉS during the years of his directorship of the Institut des Hautes Études Scientifiques. I fondly remember Odile welcoming us to their apartment overlooking the Champ-de-Mars while noticing Marcel's patient tolerance of my American manners. These personal contacts introduced me to many aspects of the French tradition-not only to such mathematical matters as the history of differential geometry in France but also to some of the charming eccentricities of everyday life in that country.

Marcel was an able leader of the IHÉS. On his watch, important matters were mainly decided by consensus, but I remember one occasion when he felt compelled to override the deliberations of the Scientific Committee, vetoing a proposal on very reasonable, common-sense grounds.

Much later, in mathematical activities involving colleagues here at Stony Brook, I came to truly appreciate the deep and beautiful contribution Marcel made to the subject of special holonomy. These results, elegantly reformulated in the thesis of Jim Simons, have led to a flourishing key area of current research in mathematics and physics. They contribute to the unifying theme underlying activities at our Simons Center for Geometry and Physics and also to certain international collaborations funded by the Simons Foundation.

\section{Jacques Lafontaine}

Since many people have already written so eloquently about Marcel Berger's mathematical work, I will not try to expand further on that theme, but will instead confine myself to a few remarks about

\section{He strongly felt that lectures should be accessible to beginners.}

to some neglected important point. He strongly felt that lectures should be accessible to beginners, at least whenever possible.

Of course, Marcel's former students all eventually became aware of the game he was playing. Nonetheless, when asking such questions he could manage to appear so bewildered that we often caught ourselves being taken in by the performance. He wasn't just an outstanding mathematician-he was an amazingly good actor!

Now that he has left us, these feigned expressions of bewilderment remain vividly alive in my memory and somehow encapsulate the essential benevolence of his attitude towards everyone around him. I have met mathematicians whose technical skills were more highly praised or highly prized, but I have never met a mathematician who had so thoroughly earned the unalloyed admiration and affection of his students.

Having now told you something about Marcel, I will conclude by telling you the story of his frequently misunderstood collaborator

Arthur L. Besse (1975-?):

Mathematical Knight of the Auvergne

Marcel was literally obsessed by certain questions that he judged to be natural and important: Riemannian analogs of Kac's celebrated problem on "hearing the shape of a drum," isosystolic inequalities, and classifying Riemannian manifolds whose geodesics are all closed and of the same length. In the early 1970s, one seemed to know surprisingly little about this last question, despite the availability of some key evidence:

- the series of examples given by the rank-1 symmetric spaces,

- the existence of metrics on spheres that enjoy this property but are geometrically different from the obvious "round" example, and

- the fact that any manifold admitting such a metric must have the cohomology ring of a rank-1 symmetric space.

Marcel thus judged the time to be ripe for a systematic attack on the problem and therefore, in May 1975, organized a workshop in the village of Besse-en-Chandesse, ${ }^{8}$ located in the highlands of the Massif Central region of south-central France. The meeting took place at a hotel named Les Mouflons, after the wild mountain sheep that wander the surrounding Volcans d'Auvergne Natural Park, under a sky full of towering cumulo-nimbus clouds. Both of these features of the area were later mentioned by the pseudonymous Arthur L. Besse in the cryptic introduction to his first mathematical publication. Even though the locale was reasonably easy to reach from Paris or Grenoble, this tranquil, bucolic setting seemed a world away from the participants' daily routine, and we felt a certain quiet pride in being able to show the foreigners in our midst around this picturesque village, with its remarkable natural and architectural environment. While some foreign participants initially seemed surprised to be

\footnotetext{
${ }^{8}$ Traditionally simply called Besse, the village is now part of a larger municipality called Besse-et-Saint-Anastaise.
} 
spending so much of their time at the table, the food was outstanding, and the delightful local cheeses seemed to help put our discussions on a fast-track to mathematical discovery.

In view of the meeting's overwhelming success, Marcel soon urged the participants to cast their newfound understanding in permanent form by jointly authoring a book. A consensus emerged that the group should write under a collective pseudonym, thereby following (in this respect only) the earlier model provided by Bourbaki. The last name of Besse was chosen in homage to the site of our fruitful meeting. Because the CNRS had designated the workshop as a "round table" for funding purposes, it was natural to invoke the legend of Camelot to provide the first name of Arthur. To decrease the probability of a lawsuit being brought by some real-life Arthur Besse, it was then decided that the name should be further embellished by the addition of an American-style middle initial, abbreviating the undisclosed middle name of Lancelot. Such was the birth of Arthur L. Besse.

As soon as the meeting
The writing had $a$ catalytic effect. ended, Arthur and his collaborators got to work. The book, entitled Manifolds All of Whose Geodesics Are Closed [19], was published by Springer in 1978. The writing had a catalytic effect; as the book took shape, significant new results were obtained by members of the group, and these were then added to the book as appendices under the names of the individual authors. In one such case, the British author and his French-teacher wife submitted an appendix carefully written in beautiful French, only to be met with implacable demands from the publisher that it be translated into English! However, in the end, we did manage to wrangle one major concession: the book's introduction was published in French and takes the form of a cryptic letter bearing the signature of Arthur L. Besse, ostensibly writing from his estate at Le Faux. ${ }^{9}$ Besse's letter begins with some brief musings on a visit he received four decades earlier from a mathematically inclined general ${ }^{10}$ who had described both his grandiose vision of the whole of mathematics and his plans for a treatise on differential geometry that had somehow never come to fruition. The practical joke then continues with a wry mixture of fact and fiction concerning French mathematics, Besse's beloved home, and the contents of the book.

But Arthur Besse didn't stop there. Pleased with the success accorded to his first foray into collaborative writing, he then went on to write a second book, Einstein

\footnotetext{
${ }^{9}$ The name of this real place, located roughly a kilometer southwest of Besse-en-Chandesse, means The False or The Forgery in French.

${ }^{10}$ General Nicolas Bourbaki and Arthur L. Besse share an important commonality that is rarely noted. Bourbaki's founding conference was held July 10-17, 1935, in Besse-en-Chandesse. Yes, really!
}

Manifolds [20], which differs markedly from its predecessor in both style and scope; while the first book might be called a monograph, the second could better be termed a treatise. Preparations for this new effort obliged Besse to leave his native Auvergne for the adjoining Rouergue region, where a meeting at Espalion, 100 miles south of Besse-en-Chandesse, resulted in a broad outline of the new book in September 1977. The intellectual pleasures of our mathematical discussions were once again reinforced by those of the local gastronomy, and the weather, far milder than that at our previous meeting, allowed for a memorable excursion to the medieval pilgrimage site of Conques, some fifty kilometers to the west.

The author's royalties from the first book helped underwrite the working meetings that made the second one possible. Thicker, more classic, and less rococco than its predecessor, this second book appeared in 1987, exactly at a moment when a conjunction of scientific developments highlighted its many deep connections to the mainstream of differential geometric research. It continues to be a key reference even now and has become Arthur Besse's best known and most widely cited work.

And what of a third book? Well, it was never in the cards for a variety of reasons. In the 1970s Besse's collaborators were largely concentrated at Jussieu and in the surrounding neighborhoods of Paris; for example, the École Polytechnique was still located in Paris, on the nearby rue Descartes. But little by little, the group dispersed to the suburbs and to other regions of France. The international model of publish or perish also began to take hold in France, making it far more difficult to convince mathematicians (and especially young ones) to work quasi-anonymously, focusing on the beauty of mathematics rather than on their own personal glory.

For all these reasons, Arthur Besse eventually became content to simply lend his name to a seminar in differential geometry, first at Jussieu and later at the École Polytechnique's new location in Palaiseau. However, Arthur continued to play a role in organizing conferences from time to time. These activities have left a durable mark on mathematics in the form of various publications bearing the Besse imprimatur [1], [15], [21], [22].

One of Arthur Besse's last public acts was to organize a conference at the CIRM in Luminy, honoring both the twentieth anniversary of Einstein Manifolds and the eightieth birthday of Besse's true father, Marcel Berger. Speaking on behalf of Springer-Verlag, Arthur's old friend Catriona Byrne made the surprise announcement that a second edition of Einstein Manifolds had been published and then proceeded to provide each conference participant with a free copy. But while the conference center, located amidst the limestone cliffs that line the coast south and east of Marseille, was both functional and pleasant, it also served as a sign of the times, reminding some of us that those heady days of intimate meetings at gastronomical hotels had, alas, now become a thing of the past.

As for Arthur, it seems that he has now definitively retired to a life of leisure. But his beneficent presence will long remain with us, because the royalties generated 
by his books have been donated in perpetuity to the European Mathematical Society for the sole purpose of providing financial support to young mathematicians in developing countries.

\section{Jerry Kazdan}

Marcel Berger was a world leader in differential geometry. He had inspiring geometric vision, asking fertile questions that give insight to techniques involving both geometry and analysis.

In addition to his own fundamental research, his seminars and projects attracted a remark-

\section{He had inspiring geometric vision.}

I learned of this from a conversation with Jean-Pierre Bourguignon at a 1977 geometry conference in Berlin. I was later pleased to be able to prove [18], [19] the desired inequality.

My contribution primarily relies on convexity inequalities. It would be useful to find a more conceptual (and less technical) proof.

\section{Marie-Louise Michelsohn}

Over the years, I have always had immense fondness and respect for Marcel Berger. I was truly saddened to learn of his death, and it is not an exaggeration to say that I miss him.

I would like to communicate a side of him that many may not know by an anecdote that has stayed with me these many years and that I think of frequently.

About three decades ago Marcel and I were corresponding mathematically, which at that time was done by postal service and hand-written letters. In his first letters, he addressed me as vous, as did essentially all French male mathematicians when addressing their female colleagues In a later letter, I finally requested that he address me as $t u$, but he then replied that this would be "contre mon éducation." I replied that to use vous for women was to exclude them from the confrérie and so was not at all positive. It should be remembered here that Marcel's upbringing was particularly conservative. Nonetheless, he understood right away, and until his death I was therefore always $t u$.

This is a small illustration of the extraordinary character of Marcel Berger. I am greatly saddened by his death.

\section{Pierre Pansu}

One day in October 1979, at Misha Gromov's first lecture at Paris VII, Marcel Berger asked the audience if anyone would volunteer to take notes on the lecture series, with the idea that these notes might eventually form the basis for a book. I raised my hand. In many ways, this simple, spontaneous act determined much of my future: I would become a geometer, I would benefit from Gromov's influence, I would participate in collective book projects, and I would receive a great deal of personal attention from Marcel Berger.

Berger's fascination with Gromov's achievements meshed perfectly with his more general enthusiasm for geometry. Nevertheless, he was also fond of saying that every deep result in geometry should entail some serious input from analysis. This precept has sometimes served as a counterweight to the style of thinking that I learned from Gromov.

Berger considered collective authorship to be a perfect training ground for young mathematicians. Fortunately,

Marie-Louise Michelsohn is professor of mathematics at Stony Brook University. Her email address is $1 \mathrm{~m} @$ math. stonybook . edu. Pierre Pansu is professor of mathematics at Paris-Sud University, France. His email address is pierre. pansu@math.u-psud.fr.
Jerry Kazdan is professor of mathematics at the University of Pennsylvania. His email address is kazdan@math. upenn. edu. 
he was a model co-author. Although hardly a model pupil as a child-he was allegedly expelled from 11 schools!he was the only one in our "class" of twenty co-authors to consistently turn in his "homework" (book chapters) on time. His chapters sometimes contained key original results, and this enhanced the value of our work, because he would never have bothered to publish these results under his own name.

Berger exercised considerable care in checking (and improving) various proofs in my thesis. Although he claimed to simply be doing his duty, this was an incredible favor. During the decades that followed, his attention from afar continued to provide me with a key source of cheer and encouragement.

I never regretted raising my hand.

\section{David Ebin}

Berger and I first met in 1968 at an AMS Summer Institute in Berkeley. I had heard of him and was interested in meeting him. I saw someone I thought might be Berger chatting with other mathematicians, and so I asked, "Are you Berger?" He replied, "Yes, but there are two." Since I knew only his first initial, I then tried to be more precise, asking, "M. Berger?" And again he said,"Yes, but there are two." Eventually, I found out that the other one was Mel Berger, ${ }^{11}$ who was also at the Summer Institute.

Berger was interested in variations of structures on Riemannian manifolds due to a change in the Riemannian metric. I had recently written my thesis on the space of Riemannian metrics on a manifold and on the natural action of the diffeomorphism group of the manifold on this space. The thesis gave a convenient way to distinguish between changes in the metric that were due to diffeomorphisms and those that represented actual changes in the geometry. This turned out to be what Berger was looking for, so we discussed the matter and soon produced a joint paper [16].

Three years later, Berger and Laurent Schwartz arranged for me to give a semester of lectures at Paris VII and the École Polytechnique. They also found lodging for my wife and me in the IHÉS Residence, and it was most enjoyable. My wife, who is an amateur violinist, played in a string quartet at the Château de l'Ermitage, in nearby Gif-sur-Yvette. The Bergers also invited us to dinner twice-first with their family, and later to what might today be called a mathematician's power dinner, with the Cartans and the Thoms.

I next saw Berger at another AMS Summer Institute, in Stanford. There he gave a series of lectures on the work of Colin de Verdière. It used the heat equation to get information about geodesics and frequently involved the fundamental solution of the heat equation, FSHE, which Berger referred to as fish. After that, Berger came to visit our department in Stony Brook several times. During his last visit, he gave a course on history of mathematics,

David Ebin is professor of mathematics at Stony Brook University. His email address is ebin@math. sunysb. edu.

${ }^{11}$ Melvyn Berger's surname is pronounced Burger. perhaps because he had largely stopped doing his own research by that time.

To me, Berger was a kind, soft-spoken man of fine, strong good will. I will miss him, and I think we all will.

\section{Karsten Grove}

I feel enormously privileged and fortunate that, at an early stage of my career, two of my idols, M. Berger and W. Klingenberg, both chose to take me under their wing. I first met Berger at a small workshop in Bonn in the fall of 1971, where Berger, Klingenberg, their students, and their visitors accounted for the vast majority of the participants. Fortunately, I later had the pleasure of seeing Berger many more times, not only at Oberwolfach but also in Paris, at Luminy, and, most memorably, at the remarkable Table Ronde workshop held at Besse-en-Chandesse in 1975.

The topic of the Besse conference was Riemannian manifolds with periodic geodesic flow, and stellar presentations by Berger and his school concerning such manifolds provided the main focus of the activity there. This was the germ of what later evolved into Arthur Besse's first book, Manifolds All of Whose Geodesics Are Closed [19], which to this day covers much of what is known on the topic. This was later followed by two more Besse books, Einstein Manifolds [20] and Géométrie riemannienne en dimension 4 [1].

Among the many profound and diverse contributions Berger made to Riemannian geometry, those that most inspired and affected my own work were the ones concerning manifolds with positive sectional curvature.

Prior to 1960, the only known (simply connected) manifolds of positive curvature were the rank-one symmetric spaces, i.e., the standard spheres and projective spaces. Moreover, the celebrated Rauch-Berger-Klingenberg 1/4Pinching Theorem shows that, up to homeomorphism, ${ }^{12}$ these are the only such manifolds with curvature varying between 1 and 4; and if the manifold is not topologically a sphere, Berger moreover proved that it must actually be isometric to a rank-one symmetric space. The fact that these spaces all have diameter at least $\pi / 2$ helped inspire my own proof, with Shiohama and Gromoll, of the so-called Diameter Sphere Theorem. In conjunction with a 2001 result of Wilking, this says that a complete Riemannian manifold with sectional curvature $\geq 1$ and diameter $\geq \pi / 2$ is finitely covered by either a topological sphere or a compact rank-one symmetric space.

In the early 1960s, Berger found two additional examples [5] of positively curved manifolds by studying a class of spaces called normal homogeneous manifolds. Since then, many other manifolds of positive sectional curvature have been found, with some new construction being discovered every decade or so. A common feature of all known constructions is that they produce examples with

Karsten Grove is Kenna Professor of Mathematics at Notre Dame University. His email address is kgrove2@nd. edu.

${ }^{12}$ A 2009 paper by Brendle and Schoen shows that the conclusion even holds up to diffeomorphism; thus, an exotic sphere can never admit a 1/4-pinched metric. 
relatively large groups of symmetries, and a great deal of subsequent work has therefore focused on classifying positively curved manifolds with large isometry groups. One of the basic tools used in this area is also due to Berger, who proved [8] that any Killing field (vector field generating a one-parameter group of isometries) on an even-dimensional positively curved manifold must have a zero; similarly, in odd dimensions, two Killing fields will be dependent at some point. Yet another important tool in this context, often called the Cheeger deformation, has its roots in a deformation introduced by Berger in his analysis of what are now called Berger spheres.

As a supportive colleague with a positive and friendly outlook, Berger will be sorely missed. But as an exceptional mathematician with a tremendous impact, he will never be forgotten.

EDITOR'S NOTE. See also Berger's article on Gromov in the February 2000 Notices, "Encounter with a Geometer,"www.ams.org/notices/200002 /fea-berger.pdf and "WHAT IS...a Systole?" in the March 2008 Notices, www.ams.org/notices /200803tx080300374p.pdf.

Berger's major surveys [13], [14] are highly recommended.

\section{Cited Works by Berger and His Collaborators}

[1] L. BÉRARD-Bergery, M. Berger, and C. Houzel, eds., Géométrie riemannienne en dimension 4, Papers from the Arthur Besse seminar held at the Université de Paris VII, Paris, 1978/1979, vol. 3 of Textes Mathématiques [Mathematical Texts], CEDIC, Paris, 1981. MR769127

[2] M. BERGER, Sur les groupes d'holonomie des variétés riemanniennes, C. R. Acad. Sci. Paris 237 (1953), 472-473. MR0056346

[3] _ Sur les groupes d'holonomie des variétés riemanniennes non symétriques, C. R. Acad. Sci. Paris 237 (1953), 1306-1308. MR0059046

[4] _ Les variétés Riemanniennes (1/4)-pincées, Ann. Scuola Norm. Sup. Pisa 14 (1960), no. 3, 161-170. MR0140054

[5] _ Les variétés riemanniennes homogènes normales simplement connexes à courbure strictement positive, Ann. Scuola Norm. Sup. Pisa 15 (1961), no. 3, 179-246. MR0133083

[6] _ Sur les variétés à courbure positive de diamètre minimum, Comment. Math. Helv. 35 (1961), 28-34. MR139121

[7] _ An extension of Rauch's metric comparison theorem and some applications, Illinois J. Math. 6 (1962), 700-712. MR0143159

[8] _ Trois remarques sur les variétés riemanniennes à courbure positive, C. R. Acad. Sci. Paris Sér. A-B 263 (1966), A76-A78. MR0199823

[9] __ Sur certaines variétés à géodésiques toutes fermées, Bol. Soc. Brasil. Mat. 9 (1978), 89-96. MR552030

[10] _ Rapport sur les variétés d'Einstein, in Analysis on Manifolds (Conf., Univ. Metz, Metz, 1979) (French), vol. 80 of Astérisque, Soc. Math. France, Paris, 1980, pp. 3, 5-19. MR620166
[11]__ Une borne inférieure pour le volume d'une variété riemannienne en fonction du rayon d'injectivité, Ann. Inst. Fourier (Grenoble) 30 (1980), 259-265. MR597027

[12] _ Sur les variétés riemanniennes pincées juste audessous de 1/4, Ann. Inst. Fourier (Grenoble) 33 (1983), 135-150 (loose errata). MR699491

[13] _ Riemannian geometry during the second half of the twentieth century, Jahresber. Deutsch. Math.-Verein. 100 (1998), 45-208. MR1637246

[14] _ A Panoramic View of Riemannian Geometry, Springer-Verlag, Berlin, 2003. MR2002701

[15] _ Yves et Arthur: quelques souvenirs, Festival Yves Colin de Verdière, Ann. Inst. Fourier (Grenoble) 57 (2007), 2083-2089. MR2394536

[16] M. BERGER AND D. EBIN, Some decompositions of the space of symmetric tensors on a Riemannian manifold, J. Differential Geometry 3 (1969), 379-392. MR0266084

[17] M. BERGER, P. GAUduchon, and E. MAZET, Le spectre d'une variété riemannienne, Lecture Notes in Mathematics, Vol. 194, Springer-Verlag, Berlin-New York, 1971. MR0282313

[18] M. BERGER and J. L. KAZDAN, A Sturm-Liouville inequality with applications to an isoperimetric inequality for volume in terms of injectivity radius, and to wiedersehen manifolds, in General Inequalities, 2 (Proc. Second Internat. Conf., Oberwolfach, 1978), Birkhäuser, Basel-Boston, Mass., 1980, pp. 367-377. MR608261

[19] A. L. BESSE, Manifolds All of Whose Geodesics Are Closed, with appendices by D. B. A. Epstein, J.-P. Bourguignon, L. BérardBergery, M. Berger, and J. L. Kazdan, vol. 93 of Ergebnisse der Mathematik und ihrer Grenzgebiete [Results in Mathematics and Related Areas], Springer-Verlag, Berlin-New York, 1978. MR496885

[20] _ Einstein Manifolds, vol. 10 of Ergebnisse der Mathematik und ihrer Grenzgebiete (3) [Results in Mathematics and Related Areas (3)], Springer-Verlag, Berlin, 1987. MR867684

[21] _ Some trends in Riemannian geometry, in Duration and Change, Springer, Berlin, 1994, pp. 71-105. MR1322983

[22] __ ed., Actes de la Table Ronde de Géométrie Différentielle, En l'honneur de Marcel Berger. [In honor of Marcel Berger], Held in Luminy, July 12-18, 1992, vol. 1 of Séminaires et Congrès [Seminars and Congresses], Société Mathématique de France, Paris; distributed by American Mathematical Society, Providence, RI, 1996. MR1427752

\section{Photo Credits}

Photo of Marcel Berger and photo in Besson section courtesy of JFD/IHÉS.

Photo of Marcel Berger in the Cheeger section (CMathematisches Forschungsinstitut Oberwolfach Photo Collection; photo by Konrad Jacobs, Erlangen.

Photo of Marcel Berger in the Bourguignon section (CMathematisches Forschungsinstitut Oberwolfach Photo Collection; photo by Dirk Ferus, Berlin. 